\title{
Dekompresif kraniyektomilerde duraplasti tipi ve komplikasyon oranı: su geçirmez duraplasti ve hızlı kapama yöntemlerinin karşılaştırılması
}

\author{
Duraplasty type and complication rate in decompressive craniotomy:comparison of \\ watertight duraplasty and rapid-closure methods
}

Fatih Yakar

\begin{abstract}
Özet
Amaç: Dekompresif kraniyektomi cerrahisi, nöroşirürji pratiğinde dirençli intrakraniyal hipertansiyonu düşürmek amacıyla sık olarak kullanılan bir yöntemdir. İşlem sırasında tercih edilebilen su geçirmez ya da hızlı kapama şeklinde su geçirmez olmayan duraplasti tipleri mevcuttur. Bu çalışmanın amacı, su geçirmez olmayan duraplastilerin operasyon sonrası dönemdeki komplikasyonları arttırıp arttırmadığını tespit etmektir.

Gereç ve yöntem: Eylül 2017-Ocak 2020 tarihleri arasında, farklı endikasyonlarla dekompresif kraniyektomi yapılan 19 hasta çalışmaya dahil edildi. Hastaların demografik bilgileri, perioperatif bulguları, komplikasyonları ve klinik faydalanma oranları değerlendirilmiştir. Su geçirmez duraplasti yapılan hastalar grup 1, hızlı kapama ile su heçirmez olmayan duraplasti yapılan hastalar grup 2 olarak belirlendi.

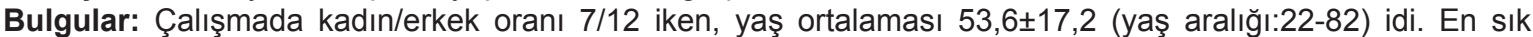
dekompresif kraniyektomi endikasyonu travmaydı (\%37, 7 hasta). Cilt altı sıvı koleksiyonu grup 1'de 1 hastada (\%12,5), grup 2'de ise 2 hastada (\%18) görüldü. Hastaların hiçbirinde yara yeri revizyonu yapılmadı. Mortal seyreden tüm vakalarda Glasgow koma skoru 8 puanın altında saptanmıştır.

Sonuç: Su geçirmez tarzda olmayan hızlı kapama duroplastisi, cerrahi komplikasyon riskini arttırmamaktadır ve güvenli/uygulanabilir bir yöntem olarak değerlendirilmektedir.
\end{abstract}

Anahtar kelimeler: Dekompresif kraniyektomi, duraplasti, su geçirmez.

Yakar F. Dekompresif kraniyektomilerde duraplasti tipi ve komplikasyon oranı: su geçirmez duraplasti ve hızlı kapama yöntemlerinin karşılaştırılması. Pam Tıp Derg 2020;13:733-737.

\begin{abstract}
Purpose: Decompressive craniectomy procedure is a frequently used method to decrease the refractory intracranial hypertension in neurosurgery practice. There are types of duraplasty that can be preferred during the procedure, which are waterproof or not waterproof in the form of rapid-closure. The aim of this study is to determine whether non-waterproof duraplasty increase complications in the postoperative period.

Materials and methods: 19 patients who underwent decompressive craniectomy with different indications between September 2017 and January 2020 were included in the study. Demographic data, perioperative findings, complications, and clinical outcomes were evaluated. Patients who underwent watertightduraplasty were determined as group 1, and those who underwent non-watertight duraplasty with rapid closure were determined as group 2.

Results: While the female / male ratio was $7 / 12$ in the study, the mean age was $53.6 \pm 17.2$ (age range:22-82). The most common indication for decompressive craniectomy was trauma (37\%, 7 patients). The subcutaneous fluid collection was revealed in 1 patient (12\%) in group 1, and 2 patients (18\%) in group 2. None of the patients underwent wound revision. In all cases with mortality, the Glasgow coma score was below 8 points.

Conclusion: Rapid-closure duraplasty that is not watertight, does not increase the risk of surgical complications, and is considered a safe/feasible method.
\end{abstract}

Key words: Decompressive craniectomy, duraplasty, watertight.

Yakar F. Duraplasty type and complication rate in decompressive craniotomy: comparison of watertight duraplasty and rapid-closure methods. Pam Med J 2020;13:733-737. 


\section{Giriş}

Dekompresif kraniyektomi (DK), medikal tedaviye yanıtsız intrakraniyal basınç artışını düşürmeyi hedefleyen cerrahi bir yöntemdir [1]. Kemik dokunun çıkarılması ve duranın genişçe açılmasıyla, beyin dokusunun kafatası tarafından sıkıştırılmadan şişmesine olanak sağlanır ve herniasyona bağlı morbidite/ mortalite'nin önüne geçilmesi hedeflenir [2, 3]. En sık endikasyonları: akut subdural hematom (ASDH), travmatik beyin hasarı (TBH), iskemik inme, subaraknoid kanama (SAK) sonrası gelişen medikasyona yanıtsız vazospazm ve dural sinüs ven trombozudur [2-6]. Günlük nöröşirürji pratiğinde sık uygulanan bir yöntem olmasına rağmen, cerrahi prosedür için ortak bir yönerge bulunmamaktadır [7].

Bu çalışmanın amacı, DK yapılan hastalarda hızlı kapama su geçirmez olmayan duraplastinin operasyon sonrası dönemde komplikasyon oranlarına etkisini araştırmaktır.

\section{Gereç ve yöntem}

Eylül 2017-Ocak 2020 tarihleri arasında farklı sebeplerle DK ve geniş duraplasti işlemi yapılan 19 hasta retrospektif olarak değerlendirildi. Su geçirmez duraplasti yapılan hastalar Grup 1, hızlı kapama ile su geçirmez olmayan duraplasti yapılan hastalar ise Grup 2 olarak tanımlandı. Hastaların yaş, cinsiyet, etyoloji, başvuru anındaki Glaskow koma skoru (GKS), operasyon süresi, komplikasyonlar, hastanede kalış süresi ve Glaskow sonuç skoru (GSS) kaydedildi. Beş puan üzerinden değerlendirilen GSS'de 1 puan ölümü, 5 puan ise iyi klinik düzelmeyi ifade etmektedir.

Hızlı kapama cerrahisi grubunda, başvuru GKS 8 puan altında olan hastalar ve intraoperatif dönemde yaşamsal bulguları stabil seyretmeyen hastalar yer almıştır. Operasyonların tamamı bulguların gelişmesinden itibaren ilk 24 saatte yapılmıştır.

Hastaların tamamına preoperatif dönemde kraniyal kontrastsız bilgisayarlı tomografi (BT) ve manyetik rezonans görüntüleme (MRG) yapıldı. Her hasta operasyon sonrası erken dönemde BT ile değerlendirilmiştir. Hastaların operasyon sonrası birinci, üçüncü ve altıncı aylarda rutin kontrolleri kraniyal BT ile yapılmıştır.
Hastaların tamamı intratrakeal genel anestezi altında opere edildi. Cerrahi insizyonun öncesinde, profilaksi için intravenöz antibiyotik uygulandı. Soru işareti şeklindeki cilt insizyonu [8] orta hatta saç çizgisinin hemen gerisinde başlayıp, lateralde paryetal eminense kadar uzatıldı ve tragusun en çok $1 \mathrm{~cm}$ önünde zygoma hizasında bitirildi. Her bir hastaya uzunluğu en az $12 \mathrm{~cm}$ boyutunda kraniyektomi yapıldı. Temporal kemikte, temporal tabana ulaşılana kadar kraniyektomi genişletildi (Resim 1). Çıkarılan kemik flep, batında subkütanöz alana yerleştirildi. Dura açılışı "+" şeklindeki insizyonla yapıldı. Su geçirmez duraplasti yapılan hastalarda greft olarak, perikraniyum dokusu ya da bacaktan alınan fasyalar kullanıldı. Sentetik dura greftleri hiçbir hastada kullanılmadı. İkinci gruptaki hastalarda ise dura parankim üzerine serildi ve açıkta kalan alanlar Surgicell (Ethicon, US) ile kapatıldı. Dura üzerine bir adet cerrahi dren yerleştirildi ve katlar anatomik planda kapatılarak operasyona son verildi. Drenler postoperatif 3 . günde çıkarıldı.

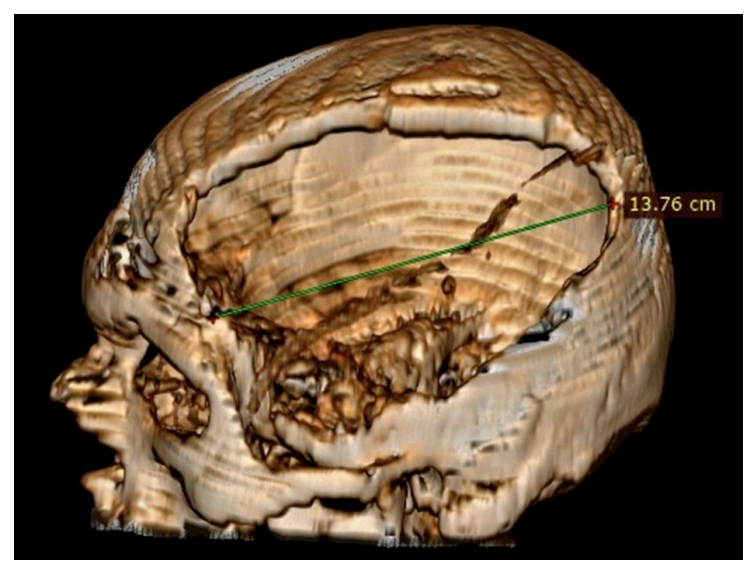

Resim 1. Postoperatif erken dönemde yapılan kraniyal BT incelemesinin 3 boyutlu rekonstrüksiyonunda, $12 \mathrm{~cm}$ üzerinde kraniyektomi yapıldığı gösterilmiştir

\section{Bulgular}

Çalışma dahilinde kadın/erkek oranı $7 / 12$ ve yaş ortalaması 53,6 $\pm 17,2$ (yaş aralığı:22-82) idi. Etyolojide en sık sebep travma iken $(\% 37$, 7 hasta), diğerleri ise iskemik inme (\%26,3, 5 hasta), hipertansif intrakraniyal kanama (HIK) ( $\% 26,3,5$ hasta), subaraknoid kanama $(\% 5,2$, 1 hasta) ve ekstradural tümör (\%5,2, 1 hasta) idi. Ekstradural tümör rezeksiyonu yapılan hastada, postoperatif dönemde cerrahi alanda kanama ve yoğun ödem gelişmesi nedeniyle DK yapılmıştır. 
Perioperatif bulgular Tablo 1'de özetlenmiştir. Grup 1'de başvuru GKS puanı 8'in altında olan hasta oranı \%50 iken, grup 2'de ise \%45 idi. Ortalama operasyon süresi hızlı kapama yapılan hastalarda daha kısa idi. Cilt altı sıvı koleksiyonu Grup 1'de 1 hastada $(\% 12,5)$, Grup 2'de ise 2 hastada (\%18) görüldü. Üç hastada da bulgular revizyon cerrahisine gerek kalmadan geriledi. Grup 2'de bir hastada subdural hematom gelişti ancak cerrahi gerektirecek boyutlarda değildi (en kalın yerinde $4 \mathrm{~mm}$ ). Grup 1'de ventriküler kanı olan 2 hastada (travma ve subaraknoid kanama) hidrosefali gelişti ve endoskopik üçüncü ventrikülostomi ile bulgular geriledi. Ortalama hastanede kalış süresi Grup 1'de daha uzun saptanmıştır. Grup 1'de 2 hastada (\%25) GSS 1 iken, Grup 2'de 8 hastada (\%73)
GSS 1 saptanmıştır. Grup 2'deki 8 ölümün ${ }^{\prime} \mathrm{i}$ HiK olan hastalardı. Mortalite gelişen hastaların tamamında GKS 8 puanın altındaydı.

\section{Tartışma}

Medikal tedaviye yanıtsız intrakraniyal basınç artışının olduğu hallerde [9], etyolojiden bağımsız olarak, DK nöroşirürji pratiğinde sık kullanılan bir uygulamadır. Cerrahi yöntem dahilinde cilt insizyonu tipi [10-12], kraniyektomi tipi/boyutu [13-15] ve duranın açılıp açılmaması [16-20] günümüze kadar tartışılagelmiştir. Günlük pratikte en çok tercih edilen yöntem geniş soru işareti tarzında Kempe cilt insizyonu kullanılarak [8], frontotemporoparyetal alanda en az $12 \mathrm{~cm}$ boyutunda kraniyektomi yapılması ve duranın açılarak parankimin rahatlatılmasıdır

Tablo 1. Her iki grubun perioperatif bulgularının karşılaştırılması

\begin{tabular}{|c|c|c|c|}
\hline & & Grup 1 & Grup 2 \\
\hline \multicolumn{2}{|c|}{ Ortalama başvuru GKS puanı } & $7,6 \pm 3,7$ & $7,4 \pm 2,9$ \\
\hline \multicolumn{2}{|c|}{ Ortalama operasyon süresi (dakika) } & $165,3 \pm 9,2$ & $127,7 \pm 19,4$ \\
\hline \multirow{3}{*}{ Komplikasyon } & Cilt altı sıvı koleksiyonu & 1 & 2 \\
\hline & Subdural hematom & - & 1 \\
\hline & Hidrosefali & 2 & - \\
\hline \multicolumn{2}{|c|}{ Ortalama hastanede kalış süresi (gün) } & $48,3 \pm 24,9$ & $23,6 \pm 25,9$ \\
\hline \multicolumn{2}{|c|}{ Glasgow Sonuç Skoru } & $2,8 \pm 1,2$ & $1,4 \pm 2,1$ \\
\hline
\end{tabular}

(GKS: Glasgow koma skoru)

[12]. Dura açıldıktan sonra yapılacak duraplastinin su geçirmez tarzda olup olmaması ise halen bir tartışma konusudur [2, 7].

Nöroşirürjiyenler tarafından duraplastinin su geçirmez tarzda yapılması geleneği Harvey Cushing ile başlamıştır. Cushing [21] tarafından kullanılan 'dura'nın iki katmanında doğru bir yaklaşımı arzu edilir ve özenle yapılmalıdır' ifadesi bu geleneğin başlangıcı olmuştur. Ancak su geçirmez tarzda olmayan duraplastilerin, BOS kaçağı ve ikincil enfeksiyon açısından su geçirmez olanlara göre daha riskli olmadığını belirten yayınlar artmaktadır [2, 7, 11, 22-25].

Vieira ve ark.'nın [2] su geçirmez olan ve olmayan hasta gruplarını karşılaştırdığı prospektif randomize kontrollü çalışmalarında, BOS kaçağı riskinde iki grup arasında anlamlı farkıılık olmamasını iki nedene bağlamışlardır. Birincisi, sadece duranın açılıp araknoide dokunulmaması nedeniyle BOS kaçağı görülmemektedir. İkinci olarak ise, geniş ve su geçirmez duraplasti yapılmaya çalışılırken durada küçük defektler kalabilmektedir. Bu defektler, tek yönlü valf mekanizması aracılığıyla BOS kaçağına zemin hazırlarlar. Bize göre ise bu mekanizmalara ek olarak, kafa içi basıncının yüksek olması nedeniyle parankim ile cilt flebi arasında potansiyel bir boşluk oluşumu söz konusu olmaması, cilt altı sıvı birikimi ya da BOS sızıntısına engel olmaktadır.

Çalışmamızda yer alan travmalı hastalarda kafa tabanı ve frontal sinüs kırığı bulunmamakla birlikte, su geçirmez olmayan duraplasti bu grupta tercih edilmemelidir. Travma nedeniyle bu hastalarda dura hasarı oluştuğunda rinore ile komplike olma olasılığı çok yüksektir. Bu hastalarda, dura hasarının gözden kaçırııması ya da hızlı kapama şeklinde yapılan su geçirmez olmayan duraplastiler rinore sonucu morbidite ve mortaliteye yol açacaktır. Grup 1'deki travmalı hastalarda cilt altı sıvı koleksiyonu 
görülmezken, Grup 2'de tek hastada görülmüş olup, cerrahi müdahale gerekmemiştir. Bu bulgular, travmalı hastalarda hızlı kapama cerrahisinin ek morbidite yaratmayacağını göstermektedir.

Hipertansif intrakraniyal kanama olan hastalarda 30 günlük ve yıllık ölüm oranları sırasıyla \%40 ve \%50'dir [26]. Ayrıca uzun dönem yoğun bakım takibi gereken hastalarda ölüm oranı \%60-80'e kadar görülebilmektedir [27]. Operasyon sırasında yaşamsal bulguları stabil seyretmeyen ve bu sebeple hızlı kapama yapılan 5 HİK hastası da yoğun bakım takiplerimizde kaybedilmiştir. Ancak bu hastalarda mortalite yara yeri kaynaklı değildir. Bir hastada ise lezyonun karşı tarafında cerrahi gerektirmeyen subdural hematom gelişmiştir. İnmeli vaka grubunda ise, 60 yaş altında ve başvuru GKS 8 puan üzeri olan 3 hastada, GSS 4 ya da 5 olup yüksek klinik faydalanma görülmüştür. 60 yaş üzerinde ve başvuru GKS 8 puan altında olan 2 hasta ise kaybedilmiştir. Bunun muhtemel sebebi, herniasyon gelişmeden operasyon yapılmış olmasıdır. İnmeli hasta grubunda, endovasküler tedavi olasılığı olmayan kliniklerde, herniasyon gelişmeden DK yapılması gerektiği kanısındayız.

Kraniyal rekonstrüksiyonun en uygun zamanlaması için de ortak bir kanı bulunmamaktadır [28]. Bu çalışmada rekonstrüksiyon postoperatif dönemde en erken 3. ayda olmak üzere, ilk bir yıl içinde yapılmıştır. Kraniyoplasti sırasında yapılacak cilt flebi diseksiyonu, parankim hasarı ve BOS sızıntısı ile morbiditeye yol açabilir. Özellikle hızı kapama yapılan hastalarda, bu olasılıkların artığı düşünülebilir fakat dikkatli bir diseksiyon ile bu komplikasyonların önüne geçilebilir. Güresir ve ark. [7] bu hasta grubunda kraniyoplasti sırasında komplikasyonların artmadığını belirtmektedir. Serimizde de herhangi bir hastada bu komplikasyonlar görülmemiştir.

Çalışmanın tek merkezli olması, retrospektif karakteri ve istatistiksel olarak anlamlı sonuç verecek sayıda hasta olmaması temel kısıtlamalardır.

Sonuç olarak, DK cerrahisi sırasında yapılan duraplastinin su geçirmez tarzda yapılmaması operasyon sonrası dönemdeki yara yeri ile ilgili komplikasyon riskini arttırmaz. Aynı zamanda operasyon süresini de kısaltmaktadır ve güvenli/uygulanabilir bir yöntem olarak değerlendirilmelidir. Hızı kapama cerrahisi ile ilgili bulgularımızın daha geniş vaka serileri ile desteklenmesi gerekmektedir.

Çıkar ilişkisi: Yazarlar herhangi bir çıkar ilişkisi olmadığını beyan eder.

\section{Kaynaklar}

1. Carter BS, Ogilvy CS, Candia GJ, Rosas HD, Buonanno F. One-year outcome after decompressive surgery for massive nondominant hemispheric infarction. Neurosurgery 1997;40:1168-1175. https:// doi.org/10.1097/00006123-199706000-00010

2. Vieira E, Guimarães TC, Faquini IV, et al. Randomized controlled study comparing 2 surgical techniques for decompressive craniectomy: with watertight duraplasty and without watertight duraplasty. J Neurosurg 2018;129:1017-1023. https://doi. org/10.3171/2017.4.JNS152954

3. Bullock MR, Chesnut R, Ghajar J, et al. Surgical management of acute subdural hematomas. Neurosurgery 2006;58:16-24. https://doi. org/10.1227/01.NEU.0000210364.29290.C9

4. Güresir E, Beck J, Vatter $\mathrm{H}$, et al. Subarachnoid hemorrhage and intracerebral hematoma: incidence, prognostic factors, and outcome. Neurosurgery 2008;63:1088-1093. https://doi.org/10.1227/01. NEU.0000335170.76722.B9

5. Vahedi K, Hofmeijer J, Juettler E, et al. Early decompressive surgery in malignant infarction of the middle cerebral artery: a pooled analysis of three randomised controlled trials. Lancet Neurol 2007;6:215222. https://doi.org/10.1016/S1474-4422(07)70036-4

6. Schwab S, Steiner T, Aschoff A, et al. Early hemicraniectomy in patients with complete middle cerebral artery infarction. Stroke 1998;29:1888-1893. https://doi.org/10.1161/01.STR.29.9.1888

7. Güresir E, Vatter H, Schuss $P$, et al. Rapid closure technique in decompressive craniectomy. J Neurosurg 2011;114:954-960. https://doi.org/10.3171/2009.12. JNS091065

8. Kempe LG. Operative Neurosurgery: volume 1 cranial, cerebral, and intracranial vascular disease. 1st ed. New York: Springer-Verlag, 1968;179-189.

9. Timofeev I, Hutchinson PJ. Outcome after surgical decompression of severe traumatic brain injury. Injury 2006;37:1125-1132. https://doi.org/10.1016/j. injury.2006.07.031

10. Yang HS, Hyun D, Oh CH, Shim YS, Park H, Kim E. A faster and wider skin incision technique for decompressive craniectomy: n-shaped incision for decompressive craniectomy. Korean J Neurotrauma 2016;12:72-76. https://doi.org/10.13004/ kjnt.2016.12.2.72 
11. Ragel BT, Klimo P, Martin JE, Teff RJ, Bakken $\mathrm{HE}$, Armonda RA. Wartime decompressive craniectomy: technique and lessons learned. Neurosurg Focus 2010;28:1-10. https://doi. org/10.3171/2010.3.FOCUS1028

12. Huang $\mathrm{X}$, Wen $\mathrm{L}$. Technical considerations in decompressive craniectomy in the treatment of traumatic brain injury. Int J Med Sci 2010;7:385-390. https://doi.org/10.7150/ijms.7.385

13. Zweckberger K, Erös C, Zimmermann R, Kim SW, Engel D, Plesnila N. Effect of early and delayed decompressive craniectomy on secondary brain damage after controlled cortical impact in mice. J Neurotrauma 2006;23:1083-1093. https://doi. org/10.1089/neu.2006.23.1083

14. Alexander E, Ball MR, Laster DW. Subtemporal decompression: radiological observations and Current surgical experience. Br J Neurosurg 1987;1:427-433. https://doi.org/10.3109/02688698708999632

15. Clark K, Nash TM, Hutchison GC. The failure of circumferential craniotomy in acute traumatic cerebral swelling. J Neurosurg 1968;29:367-371. https://doi. org/10.3171/jns.1968.29.4.0367

16. Mitchell P, Tseng M, Mendelow AD. Decompressive craniectomy with lattice duraplasty. Acta Neurochir 2004;146:159-160. https://doi.org/10.1007/s00701003-0186-z

17. Ruf B, Heckmann M, Schroth I, et al. Early decompressive craniectomy and duraplasty for refractory intracranial hypertension in children: results of a pilot study. Crit Care 2003;7:133-138. https://doi. org/10.1186/cc2361

18. Kilincer C, Simsek O, Hamamcioglu MK, Hicdonmez T, Cobanoglu S. Contralateral subdural effusion after aneurysm surgery and decompressive craniectomy: case report and review of the literature. Clin Neurol Neurosurg 2005;107:412-416. https://doi.org/10.1016/j. clineuro.2004.09.018

19. Yang XJ, Hong GL, Su SB, Yang SY. Complications induced by decompressive craniectomies after traumatic brain injury. Chin J Traumatol 2003;6:99-103.

20. Kombogiorgas D, Jatavallabhula NS, Sgouros S, Josan V, Walsh AR, Hockley AD. Risk factors for developing epilepsy after craniotomy in children. Childs Nerv Syst 2006;22:1441-1445. https://doi.org/10.1007/s00381006-0117-4

21. Cushing $H$. Surgery of the head. In: Keen WW, ed. Surgery, its principles and practice. 3rd ed. Saunders 1908:17-276.

22. Barth M, Tuettenberg J, Thomé C, Weiss C, Vajkoczy P, Schmiedek P. Watertight dural closure: is it necessary? A prospective randomized trial in patients with supratentorial craniotomies. Neurosurgery 2008;63:352-358. https://doi.org/10.1227/01. NEU.0000310696.52302.99
23. Sade B, Oya S, Lee JH. Non-watertight dural reconstruction in meningioma surgery: results in 439 consecutive patients and a review of the literature. J Neurosurg 2011;114:714-718. https://doi. org/10.3171/2010.7.JNS10460

24. Holland M, Nakaji P. Craniectomy: surgical indications and technique. Operative Techniques in Neurosurgery 2004;7:10-15. https://doi.org/10.1053/j. otns.2004.04.006

25. Kolias AG, Kirkpatrick PJ, Hutchinson PJ. Decompressive craniectomy: past, present and future. Nature Reviews Neurology 2013;9:405-415. https:// doi.org/10.1038/nrneurol.2013.106

26. Broderick JP, Brott TG, Duldner JE, Tomsick T, Huster G. Volume of intracerebral hemorrhage: a powerful and easy-to-use predictor of 30-day mortality. Stroke 1993;24:987-993. https://doi.org/10.1161/01. STR.24.7.987

27. Passero S, Burgalassi L, D'andrea P, Battistini N. Recurrence of bleeding in patients with primary intracerebral hemorrhage. Stroke 1995;26:1189-1192. https://doi.org/10.1161/01.STR.26.7.1189

28. Carvi Y Nievas MN, Höllerhage HG. Early combined cranioplasty and programmable shunt in patients with skull bone defects and CSF-circulation disorders. Neurol Res 2006;28:139-1344. https://doi. org/10.1179/016164106X98008

Çalışma, retrospektif bir çalışma olup Eylül 2017 başlayıp, 2019 yılı Aralık 2019 sonunda tamamlandığı için etik kurul onayı alınmamıştır. 